\title{
A High Pressure Matrix-Assisted Laser Desorption Ion Source for Fourier Transform Mass Spectrometry Designed to Accommodate Large Targets with Diverse Surfaces
}

\author{
Peter B. O'Connor, Bogdan A. Budnik, Vera B. Ivleva, Parminder Kaur, \\ Susanne C. Moyer, Jason L. Pittman, and Catherine E. Costello \\ Department of Biochemistry, Boston University School of Medicine, Boston, Massachusetts, USA
}

\begin{abstract}
A new design for a high pressure MALDI-FTMS instrument is described and initial data are shown. The instrument incorporates a large, $10 \mathrm{~cm} \times 10 \mathrm{~cm}$, sample translation stage to accommodate and position the MALDI target. The new instrument allows coupling to a wide variety of surface techniques such as gel electrophoresis or surface plasmon resonance. Coupling to thin layer chromatography is shown. Furthermore, a new nozzle design allows high pressure collisional cooling sufficient to stabilize gangliosides while minimizing the gas load on the system. (J Am Soc Mass Spectrom 2004, 15, 128-132) (C) 2004 American Society for Mass Spectrometry
\end{abstract}

$\mathrm{M}$ atrix-assisted laser desorption/ionization (MALDI) [1-5] is now widely used in biological research. It has the advantage of higher throughput than electrospray ionization, but the disadvantage of being limited to low charge states. However, as the field of proteomics crucially requires high throughput mass spectrometry (MS), and as biochemists are becoming more and more interested in simple, high performance instrumentation, MALDI has become the preferred ionization method for many of them.

MALDI ionization is traditionally coupled to a timeof-flight (TOF) mass spectrometer [6] as the pulsed nature of MALDI is highly compatible with pulsed detection methods like TOF MS. However, any trappedion mass spectrometer is also a pulsed detector and, as the biochemistry problems require high performance instrumentation, coupling MALDI to Fourier-transform ion cyclotron resonance mass spectrometers [7, 8] (FTICRMS or FTMS) is clearly a promising combination. An automated MALDI-FTMS [9-11] has been demonstrated to outperform MALDI-TOF MS on mass accuracy [12], sensitivity [13, 14], resolution [15], and tandem MS capabilities [16].

Furthermore, the new development of high pressure MALDI [17-21] has demonstrated the ability to cool the internal vibrational energy of ions, even to the point of

Published online December 2, 2003

Address reprint requests to Dr P. B. O'Connor, Mass Spectrometry Resource, Department of Biochemistry, Boston University School of Medicine, 715 Albany Street, R806, Boston, MA 02118, USA. E-mail: poconnor@bu.edu being able to minimize or prevent loss of sialic acid residues on gangliosides [22]. This development thus extends the application of MALDI into a range of labile molecules that previously were unable to be investigated. While several new commercial MALDI-FTMS instruments exist, none of them include these high pressure MALDI capabilities.

The prototype instrument [20], while it served to prove that collisional cooling of the vibrational energy is possible [22], was severely limited in size and number of samples that could be handled. Therefore, to extend the utility of this technique, a new external MALDIFTMS instrument was designed which allows high pressure MALDI ionization to be done on a large, flat sample plate mounted on a 2-D sample translation stage.

\section{Instrument Design}

The basic purpose of this instrument is to allow high pressure MALDI-FTMS using a high throughput, large area, 2-D sample translation stage; a diagram of the final instrument design is shown in Figure 1. The $X Y$ stage (Figure 1a) was purchased from Parker-Daedal (series 800 stages, Irwin, PA) and mounted in a custombuilt vacuum chamber. The stage was controlled by two stepper motors (Empire Magnetics NEMA23, Rohnert Park, CA) run by two stepper motor drivers (Parker Compumotor Zeta4, Irwin, PA). This stepper motor system was controlled by a programmable controller (Parker 6k, Irwin, PA), which was in turn programmed 


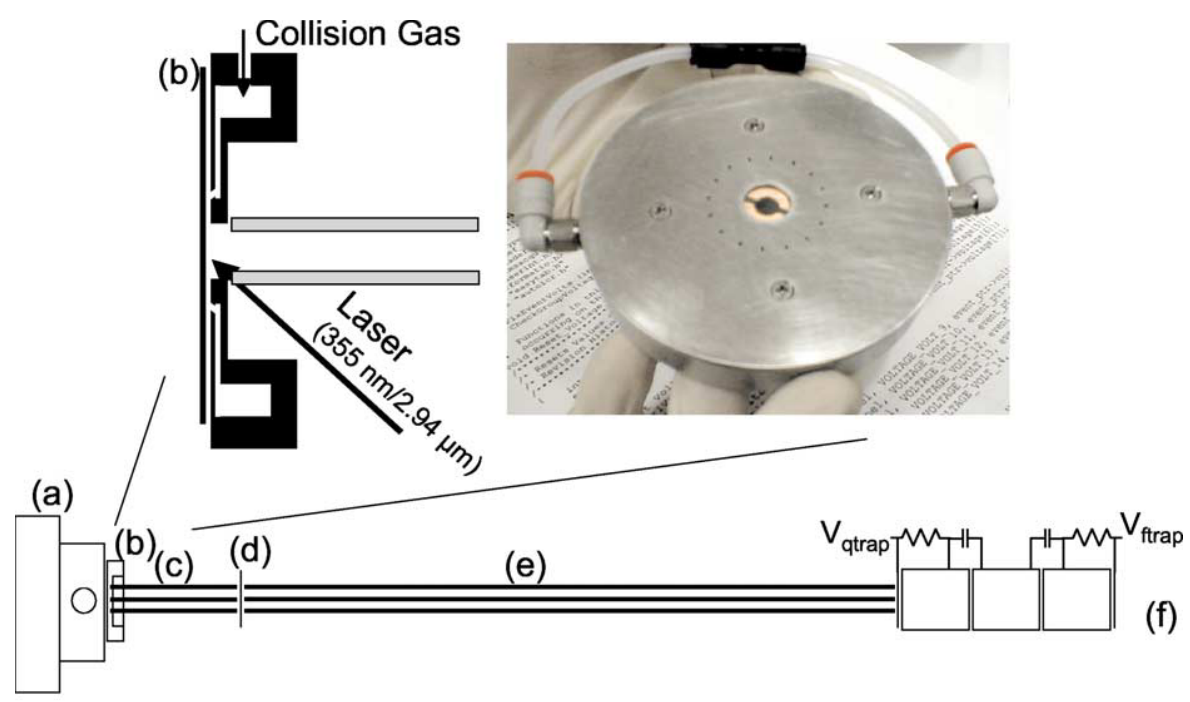

Figure 1. A diagram of the instrument showing (a) XY stage; (b) gas-expansion chamber, transfer channels, and nozzles with a photograph of the gas channel plate; (c) accumulation hexapole, (d) gate valve; (e) transfer hexapole; (f) ICR Cell.

by RS232 from a computer. Software was written inhouse to program the Parker $6 \mathrm{k}$ controller. This software was designed to allow the user to load a digital photograph of the sample plate and click the mouse cursor on the point of interest on the photograph to position that point under the laser. This capability added the flexibility to handle any material which can be attached to the target as a desorption surface.

MALDI target plates were inserted into an electrically isolated bracket mounted on top of the 2-D sample translation stage and forced forward into position by two ribbons of spring steel. A DAC set the potential on the plates to $+3 \mathrm{~V}_{\mathrm{dc}}$. Experimentally, values from 0-8 $\mathrm{V}_{\mathrm{dc}}$ are acceptable with a two fold sensitivity improvement at $3 \mathrm{~V}_{\mathrm{dc}}$ compared to either end of the range. The mounting bracket was designed to accept plates of the same size and shape as standard microtiter plates, allowing the target plates to be analyzed on other mass spectrometers that employ the same format. Furthermore, many sample handling and spotting robots exist for microtiter plates facilitating future automation of the system.

A Bioscope UV+ laser (Bioptic Lasersysteme, Berlin, Germany) with two laser heads: one Nd:YAG (frequency tripled to $355 \mathrm{~nm}, 1 \mathrm{~mJ} / 5 \mathrm{~ns}$ pulse, $20 \mathrm{~Hz}$ ) and an Er:YAG $(2940 \mathrm{~nm}, 7 \mathrm{~mJ} / 100 \mathrm{~ns}$ pulse, $5 \mathrm{~Hz})$ was used. The two laser beams were focused through a 200 $\mathrm{mm}$ sapphire lens (Laser Components, Olching, Germany) to a $\sim 0.5 \mathrm{~mm}$ spot, and both lasers were positioned using three $25.4 \mathrm{~mm}$ diameter high reflectance mirrors (UV: ThorLabs Newton, NJ; IR: Laser Components). The final UV mirror was mounted on a flipping gimbal mount, allowing it to be shifted out of the beam path when the IR laser is being used. Only one laser wavelength can be used at a time.

The high pressure gas pulse was introduced via a pulsed valve through a $1.6 \mathrm{~mm}$ i.d. Teflon tube to the gas expansion chamber (Figure 1b). The gas then flowed out of this chamber through 16 channels (1.6 $\mathrm{mm}$ wide $\times 0.8 \mathrm{~mm}$ high $\times 9 \mathrm{~mm}$ long) and out through 16 nozzles $(0.6 \mathrm{~mm}$ diameter, $0.8 \mathrm{~mm}$ long cylinders ) concentrically arranged with $12.7 \mathrm{~mm}$ diameter and angled inward at $45^{\circ}$. This design provided jets of gas that expand and flow inward toward the sample spot where they combine and flow into the hexapole. The pressure in the plume region was $\sim 1-5$ mbar based on gas flow calculations, but these values must be considered crude estimates because of the large number of assumptions that must be made in the calculations.

Ions were desorbed from the sample target plate and captured in the first accumulation hexapole (Figure 1c). The entrance plate, an OFHC copper electrode with a slot cut horizontally for the laser and visualization optics, was held at $1 \mathrm{~V}_{\mathrm{dc}}$ during desorption and slowly ramped to $10 \mathrm{~V}_{\mathrm{dc}}$ while the ions were trapped. The DC bias voltage of the hexapole was held at $-5 \mathrm{~V}_{\mathrm{dc}}$ during desorption and ramped to $0 \mathrm{~V}_{\mathrm{dc}}$ prior to ejection. Hexapole RF amplitude and frequency (typically 500 $\mathrm{V}_{p-p}$ and $862 \mathrm{kHz}$ ) were controlled by a previously described RF oscillator [23]. The hexapole exit electrode, a small OFHC copper plate with a $\sim 5 \mathrm{~mm}$ orifice, was held at $+10 \mathrm{~V}_{\mathrm{dc}}$ during trapping and pulsed to $-10 \mathrm{~V}_{\mathrm{dc}}$ during ejection. The transfer hexapole (Figure 1e) offset was held at $-25 \mathrm{~V}_{\mathrm{dc}}$ with RF amplitude and frequency $\left(\sim 500 \mathrm{~V}_{p-p}\right.$ and $\left.\sim 900 \mathrm{kHz}\right)$ controlled using a homebuilt LC Tank circuit driven by a high power amplifier (ENI 2100L, Rochester, NY) which was driven in turn by a signal generator (Wavetek, model 19 0-2 MHz, San Diego, CA) tuned to the resonance frequency of the tank. Both hexapoles were constructed with a $9.5 \mathrm{~mm}$ inscribed diameter using $4.76 \mathrm{~mm}$ titanium rods to avoid magnetization.

The ICR cell (Figure 1f) was a Beu-type [24] capacitively coupled cylindrical cell with front and back 
trapping plates connected as shown in Figure 1. The cell is constructed of OFHC copper and Macor. The back trap plate is held at $20 \mathrm{~V}_{\mathrm{dc}}$ during ion injection, and the front trap plate is held at ground and raised to $20 \mathrm{~V}_{\mathrm{dc}}$ to trap the ions. The $\mathrm{RC}$ time constant of $\sim 1 \mathrm{~ms}$ was chosen so that, while the outer trap plates can change in $\sim 1 \mu \mathrm{s}$, the inner ones slowly ramped to their final values over several ms. The magnet is a Cryomagnetics (Oak Ridge, TN) 7T active shielded ICR magnet with a $127 \mathrm{~mm}$ room temperature bore and a $+/-10 \mathrm{ppm}$ central magnetic field homogeneity over a $50 \mathrm{~mm}$ diameter by $100 \mathrm{~mm}$ long cylinder. Transients were acquired using an Ionspec Omega system (Irvine, CA.)

The pulse sequence involved three parts (following the quench pulse): external multishot accumulation [25], ion transfer/trapping, and excitation/detection. The Bioscope UV+ laser was programmed so that, following a single TTL trigger, it pre-fired five shots (without Q-switch) to warm up the laser, then fired 5-20 laser shots. Ions generated by these laser shots were accumulated in the hexapole prior to transfer to the cell. The pulse valve, backed by $\sim 600$ mbar argon, was opened during the multishot accumulation event increasing source chamber pressure to $\sim 10^{-3} \mathrm{mbar}$. The cell pressure increased to $\sim 10^{-7}$ mbar at this time. After the laser desorption event, the pulse valve closed, and a delay of $\sim 3 \mathrm{~s}$ allowed the pressure to drop to $\sim 10^{-7}$ mbar in the source prior to ion transfer.

Ion transfer occurred by first ramping the hexapole front plate and offset to $10 \mathrm{~V}_{\mathrm{dc}}$ and $0 \mathrm{~V}_{\mathrm{dc}}$, respectively, over $1 \mathrm{~s}$. Ions then were extracted from the hexapole by shifting the rear hexapole trap plate from 10 to $-10 \mathrm{~V}_{\mathrm{dc}}$. Transfer times vary from 0.75 to $3 \mathrm{~ms}$ depending on the expected $m / z$ range of the ions. Ions were excited by a frequency sweep ( $8 \mathrm{~ms}, 90 \mathrm{~V}_{p-p}, m / z 215-1500$ range) and detected at $1 \mathrm{MHz}$ into 2 MWord (12 bit) data files. Spectra were analyzed using the Boston University data analysis software (BUDA) [26].

The first spectra shown were acquired in a prior design that did not include a gate valve between the source and the cell. This arrangement was not ideal as changing the sample plate required a bakeout. Addition of a new gate valve design to the system allowed changing of sample plates within $\sim 15 \mathrm{~min}$.

\section{Results and Discussion}

We previously reported high pressure collisional cooling of gangliosides [22], but due to the difficulty in determining the pressure in the MALDI plume region, it was necessary to demonstrate similar collisional cooling with this new design. For this reason, ganglioside standards GM2, GD1a, and GT1b (mono-, di-, and tri-sialylated, respectively) were ionized and detected with the new instrument (Figure 2). The three ganglioside samples were desorbed directly from thin layer chromatography (TLC) plates $[27,28]$ using sinapinic acid as the matrix [29]. These three spectra show minimal or no loss of the sialic acid moieties, indicating

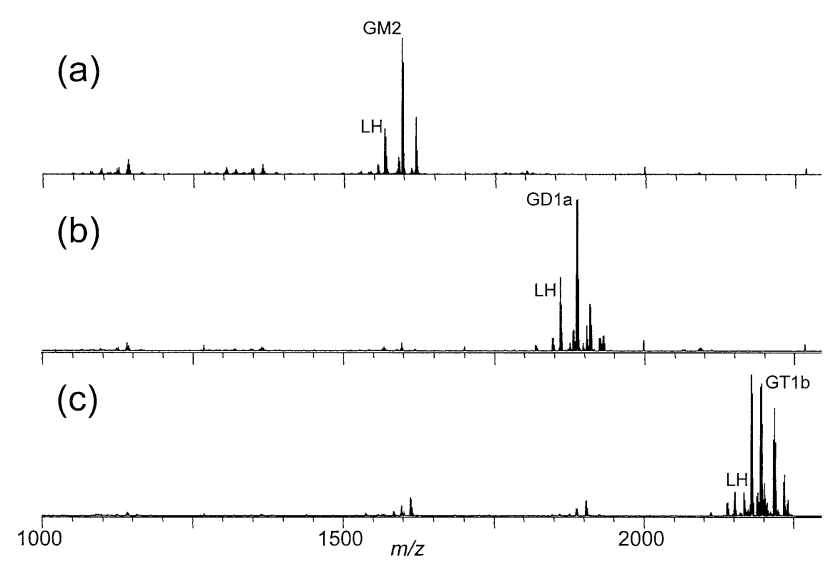

Figure 2. High pressure TLC-MALDI-FTMS spectra of three gangliosides (a) GM2, (b) GD1a, and (c) GT1b.

that the cooling is at least as effective as was seen with the previous design. Additionally, sinapinic acid was used in this case while 6-azo-2-thiothimine (ATT) was used for the previous work. Since sinapinic acid is generally considered to be a hotter matrix than ATT [30, 31] cooling may be more effective with the new instrument design.

These gangliosides were desorbed directly from $2 \times$ $4 \mathrm{~cm}$ TLC plates. The ganglioside standards were individually deposited (not mixed) along the bottom of the TLC plate and run vertically using a standard separation method. The plate was then attached to the MALDI sample target using double sided tape. Sinapinic acid solution was deposited on top of the sample and allowed to dry. Details of this method will be reported separately [29].

Two other labile species were tested with the new high pressure MALDI-FTMS instrument (Figure 3). The first, $\mathrm{P}_{14} \mathrm{R}$ (Figure 3a), is a labile peptide used as a

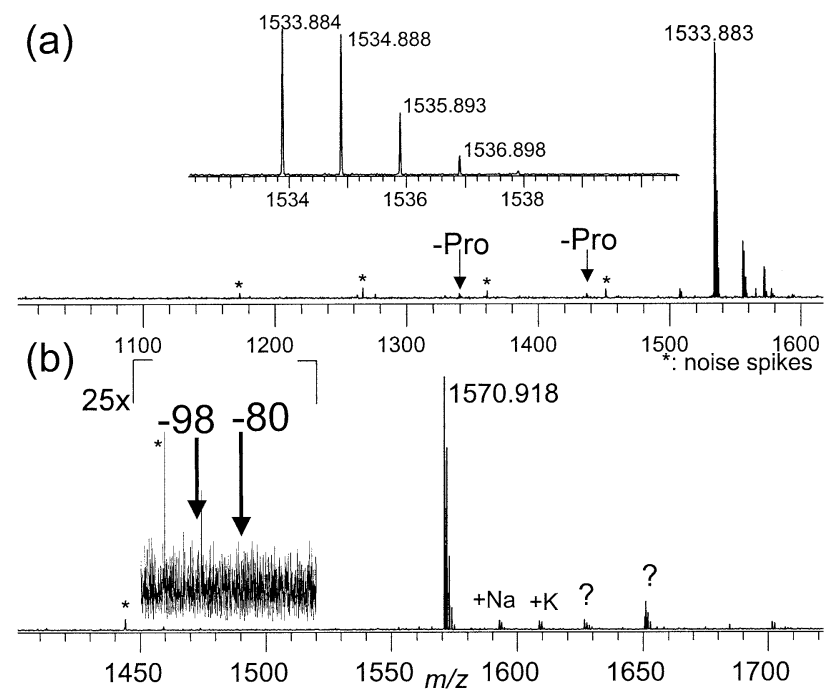

Figure 3. High pressure MALDI-FTMS spectra of two labile species, (a) $\mathrm{P}_{14} \mathrm{R}$ peptide and (b) 3 femtomoles of a phosphopeptide. 
standard calibration compound for metastable fragmentation recorded with MALDI-TOF mass spectrometers, owing to its tendency to cleave at each proline residue, forming a clear y-ion series [32]. This spectrum shows none of the typical fragments, despite the $\sim 15 \mathrm{~s}$ delay between ionization and detection (compared to $\sim 100 \mu$ s commonly used for exploration of metastable ions in MALDI-TOF mass spectrometry). The large number of low intensity peaks can be attributed to electronic noise spikes (as evidenced by the absence of isotope peaks). This problem was solved later by removing ground loops and proper shielding of all electronic equipment and cables used for this experiment. The second labile species (Figure $3 b$ ) is a phosphopeptide with sequence RRREEE(pS)EEEAA. Clearly, there are none of the characteristic $-79.966 \mathrm{Da}$ and -97.977 Da phosphate losses, this result indicates that there is sufficient cooling to stabilize the phosphopeptides.

\section{Detection Limits}

This source was designed so that ions would be desorbed along the ion optical axis for improved sensitivity compared with desorption from the angled surface used in the commercial MALDI-FTMS instrument. The prototype high pressure MALDI-FTMS instruments [13, 20] demonstrated detection limits in the low atto- to low femtomole range, which had been impossible to achieve with the commercial MALDI-FTMS instrument. While the full sensitivity advantages of this new design have not yet been completely explored, Figure 3 clearly shows that the low femtomole sensitivity range is readily accessible.

In the high pressure region ( $~ 1-10$ mbar) required for collisional cooling, the aerodynamic effects of the cooling gas must be considered in the design of the ion optics. The prototype HP-MALDI source used a small, completely enclosed region that allowed the source volume to be raised to the 1-10 mbar range upon application of a relatively modest pulse of collision gas. Additionally, most of the gas flowed out into the linear hexapole ion trap, picking up the ions, cooling them, and transporting them into the ion trap before being pumped away. This system, with such a large XY stage, required either completely enclosing the large volume of the stage, or a gas jet arrangement that would focus the collision gas on the MALDI plume region. Several variants of the gas jet were evaluated, with the best design was reported here (Figure $1 \mathrm{~b}$ ). This arrangement balances the volume of gas needed to achieve cooling with simplicity of implementation.

\section{Sample Plates}

This system allows placement of hundreds or thousands of MALDI samples on a target plate, greatly increasing throughput, but it also allows the use of alternative surfaces such as the Bruker Anchor Chip technology $[33,34]$ or desorption from various mem- branes. Furthermore, as demonstrated by desorption from TLC plates (Figure 2), this system can be modified to couple a wide variety of surface techniques to HPMALDI-FTMS. One primary advantage to this design is that, unlike traditional (axial) MALDI-TOF MS, it is largely insensitive to surface topography. The potential variety of coupling methods possible is therefore extensive.

\section{Acknowledgments}

The authors thank Dr. Ansgar Brock for suggesting the Parker XY stage. This project was aided by the Boston University Scientific Instrument Facility, and has been funded in part with Federal funds from the National Center for Research Resources (P41RR10888), and by the National Heart, Lung, and Blood Institute (N01-HV-28178). JLP is partially supported by MDS Sciex under a research collaborative agreement.

\section{References}

1. Karas, M.; Bachmann, D.; Hillenkamp, F. Influence of the Wavelength in High-Irradiance Ultraviolet Laser Desorption Mass Spectrometry of Organic Molecules. Anal. Chem. 1985, 57, 2935-2939.

2. Karas, M. I.; Bachmann, D.; Bahr, U.; Hillenkamp, F. MatrixAssisted Ultraviolet Laser Desorption of Non-Volatile Compounds. Int. J. Mass Spectrom. Ion Processes 1987, 78, 53-68.

3. Karas, M.; Hillenkamp, F. Laser Desorption Ionization of Proteins with Molecular Masses Exceeding 10,000 daltons. Anal. Chem. 1988, 60, 2299-2301.

4. Tanaka, K.; Waki, H.; Ido, Y.; Akita, S.; Yoshida, Y.; Yoshida, T. Protein and Polymer Analyses up to $m / z$ 100,000 by Laser Ionization Time-of-Flight Mass Spectrometry. Rapid Commun. Mass Spectrom. 1988, 2, 151-153.

5. Karas, M.; Bahr, U.; Fournier, I.; Gluckmann, M.; Pfenninger, A. The Initial-Ion Velocity as a Marker for Different Desorption-Ionization Mechanisms in MALDI. Int. J. Mass Spectrom. Ion Processes 2003, 226, 239-248.

6. Cotter, R. J. Time-of-Flight mass Spectrometry; American Chemical Society: Washington, DC, 1994, pp 1-326.

7. Comisarow, M. B.; Marshall, A. G. Fourier Transform Ion Cyclotron Resonance Spectroscopy. Chem. Phys. Lett. 1974, 25, 282-283.

8. Marshall, A. G. Milestones in Fourier Transform Ion Cyclotron Resonance Mass Spectrometry Technique Development. Int. J. Mass Spectrom. Ion Processes 2000, 200, 331-356.

9. Peters, E. C.; Brock, A.; Horn, D. M.; Phung, Q. T.; Ericson, C.; Salomoon, A. R.; Ficarro, S. B.; Brill, L. M. An Automated LC-MALDI FT-ICR MS Platform. LC GC Europe 2002, 2-7 July.

10. Brock, A.; Horn, D. M.; Peters, E. C.; Shaw, C. M.; Ericson, C.; Phung, Q. T.; Saloma, A. R. An Automated Matrix-Assisted Laser Desorption/Ionization Quadrupole Fourier Transform Ion Cyclotron Resonance Mass Spectrometer for "Bottom-Up" Proteomics. Anal. Chem 2003, 75, 3419-3428.

11. Ericson, C.; Phung, Q. T.; Horn, D. M.; Peters, E. C.; Fitchett, J. R.; Ficarro, S. B.; Saloma, A. R.; Brill, L. M.; Brock, A. An Automated Noncontact Deposition Interface for Liquid Chromatography Matrix-Assisted Laser Desorption/Ionization Mass Spectrometry. Anal. Chem. 2003, 75, 2309-2315.

12. O'Connor, P. B.; Costello, C. E. Internal Calibration on Adjacent Samples (InCAS) with Fourier Transform Mass Spectrometry. Anal. Chem. 2000, 72, 5881-5885.

13. Baykut, G.; Jertz, R.; Witt, M. Matrix-Assisted Laser Desorption/Ionization Fourier Transform Ion Cyclotron Resonance 
Mass Spectrometry with Pulsed In-Source Collision Gas and In-Source Ion Accumulation. Rapid Commun. Mass Spectrom. 2000, 14, 1238-1247.

14. Valaskovic, G. A.; Kelleher, N. L.; Little, D. P.; Aaserud, D. J.; McLafferty, F. W. Attomole-Sensitivity Electrospray Source for Large-Molecule Mass Spectrometry. Anal. Chem. 1995, 67, 3802-3805.

15. He, F.; Hendrickson, C. L.; Marshall, A. G. Baseline Mass Resolution of Peptide Isobars: A Record for Molecular Mass Resolution. Anal. Chem. 2001, 73, 647-650.

16. Mirgorodskaya, E.; O'Connor, P. B.; Costello, C. E. A General Method for Precalculation of Parameters for Sustained Off Resonance Irradiation/Collision-Induced Dissociation. J. Am. Soc. Mass Spectrom. 2002, 13, 318-324.

17. Loboda, A. V.; Krutchinsky, A. N.; Bromirski, M.; Ens, W.; Standing, K. G. A Tandem Quadrupole/Time-of-Flight Mass Spectrometer with a Matrix-Assisted Laser Desorption/Ionization Source: Design and Performance. Rapid Commun. Mass Spectrom. 2000, 14, 1047-1057.

18. Laiko, V. V.; Baldwin, M. A.; Burlingame, A. L. Atmospheric Pressure Matrix-Assisted Laser Desorption/Ionization Mass Spectrometry. Anal. Chem. 2000, 72, 652-657.

19. Laiko, V. V.; Moyer, S. C.; Cotter, R. J. Atmospheric Pressure MALDI/Ion Trap Mass Spectrometry. Anal. Chem. 2000, 72, $5239-5243$.

20. O'Connor, P. B.; Costello, C. E. A High Pressure MatrixAssisted Laser Desorption/Ionization Fourier Transform Mass Spectrometry Ion Source for Thermal Stabilization of Labile Biomolecules. Rapid Commun. Mass Spectrom. 2001, 15, 1862-1868.

21. Moyer, S. C.; Cotter, R. J. Atmospheric Pressure MALDI. Anal. Chem. 2002, 74, 469A-476A.

22. O'Connor, P. B.; Mirgorodskaya, E.; Costello, C. E. High Pressure Matrix-Assisted Laser Desorption/Ionization Fourier Transform Mass Spectrometry for Minimization of Ganglioside Fragmentation. J. Am. Soc. Mass Spectrom. 2002, 13, 402-407.

23. O'Connor, P. B.; Costello, C. A.; Earle, W. E. A High Voltage RF Oscillator for Driving Multipole Ion Guides. J. Am. Soc. Mass Spectom. 2002, 13, 1370-1375.

24. Beu, S. C.; Laude, D. A., Jr. Open Trapped Ion Cell Geometries for FT/ICR/MS. Int. J. Mass Spectrom. Ion Processes 1992, 112, 215-230.
25. O'Connor, P. B.; Costello, C. E. Application of Multishot Acquisition in Fourier Transform Mass Spectrometry. Anal. Chem. 2000, 72, 5125-5130.

26. O'Connor P. B. Boston University Data Analysis. 2002. http:// www.bumc.bu.edu/ftms.

27. Juhasz, P.; Costello, C. E. Matrix-Assisted Laser Desorption Ionization Time-of-Flight Mass Spectrometry of Underivatized and Permethylated Gangliosides. J. Am. Soc. Mass Spectrom. 1992, 3, 785-796.

28. Guittard, J.; Hronowski, X. P. L.; Costello, C. E. Direct MatrixAssisted Laser Desorption/Ionization Mass Spectrometric Analysis of Glycosphingolipids on Thin Layer Chromatographic Plates and Transfer Membranes. Rapid Commun. Mass Spectrom. 1999, 13, 1838-1849.

29. Ivleva, V. B., Elkin, Y. N., Budnik, B. A., Moyer, S. C., Costello, C. E., O'Connor, P. B. Coupling Thin Layer Chromatography with High Pressure Matrix Assisted Laser Desorption/Ionization Fourier Transform Mass Spectrometry for the Analysis of Ganglioside Mixtures, unpublished.

30. Beavis, R. C.; Chait, B. T. Cinnamic Acid Derivatives as Matrices for Ultraviolet Laser Desorption Mass Spectrometry of Proteins. Rapid Commun. Mass Spectrom. 1989, 3, 432-435.

31. Brown, R. S.; Carr, B. L.; Lennon, J. J. Factors that Influence the Observed Fast Fragmentation of Peptides in MatrixAssisted Laser Desorption. J. Am. Soc. Mass Spectom. 1996, 7, 225-232.

32. For peptide ion fragmentation nomenclature, see: (a) Roepstorff, P., Fohlman, J. Proposal for a Common Nomenclature for Sequence Ions in Mass Spectra of Peptides. Biomed. Mass Spectrom. 1984, 11, 601; as modified by (b) Biemann, K. Contributions of Mass Spectrometry to Peptide and Protein Structure. Biomed. Environ. Mass Spectrom. 1988, 16, 99-111.

33. Johnson, T.; Bergquist, J.; Ekman, R.; Nordhoff, E.; Schurenberg, M.; Kloppel, K. D.; Muller, M.; Lehrach, H.; Gobom, J. A CE-MALDI Interface Based on the Use of Prestructured Sample Supports. Anal. Chem. 2001, 73, 1670-1675.

34. Nordhoff, E.; Schurenberg, M.; Thiele, G.; Lubbert, C.; Kloeppel, K. D.; Theiss, D.; Lehrach, H.; Gobom, J. Sample Preparation Protocols for MALDI-MS of Peptides and Oligonucleotides Using Prestructured Sample Supports. Int. J. Mass Spectrom. Ion Processes 2003, 226, 163-180. 